\title{
Natal dispersal in monogamous owl monkeys (Aotus azarai) of the Argentinean Chaco
}

\author{
E. Fernandez-Duque ${ }^{1,2,3)}$ \\ $\left({ }^{1}\right.$ Department of Anthropology, University of Pennsylvania, Philadelphia, PA, USA; \\ ${ }^{2}$ CECOAL, Conicet, 3400 Corrientes, Argentina)
}

(Accepted: 3 December 2008)

\begin{abstract}
Summary
This study offers a detailed description of natal dispersal patterns in owl monkeys (Aotus azarai) and evaluates the extent and characteristics of sex-biased dispersal in this monogamous mammal. Owl monkeys are small, territorial primates that live in socially monogamous groups in the Argentinean Chaco. Between 1997 and 2007 we recorded the disappearance or dispersal of 102 individuals born in 24 social groups. All individuals, both males and females, left their natal group, and they did so when they were between 2.2 and 4.9 years of age. Most dispersal events occurred immediately before or during the birth season and very few of them occurred during the mating season. Males and females did not differ significantly in the timing of dispersal, the age when they dispersed or how far they dispersed. Dispersals during the harsher Fall/Winter season were associated with the eviction of one or both adults in the group. The limited data on the fate of dispersed individuals suggests that natal dispersal is a highly risk event in the life of owl monkeys. The data also provide adequate support for the inbreeding avoidance hypothesis for natal dispersal in this species.
\end{abstract}

Keywords: monogamy, natal dispersal, eviction, inbreeding, birth, mating.

\section{Introduction}

The evolution, function and mechanisms of dispersal have received considerable attention from evolutionary biologists, given the significant impact of dispersal patterns on the fitness of individuals and the structure of populations (Greenwood, 1983; Chepko-Sade \& Halpin, 1987; Pusey, 1987;

\footnotetext{
3) E-mail address: eduardof@ sas.upenn.edu 
Johnson \& Gaines, 1990; Clobert et al., 2001, Lawson Handley \& Perrin, 2007). Historically, evolutionary explanations for dispersal have proposed a close relationship between dispersal patterns and mating systems (Nagy et al., 2007), and it has been suggested that, among mammals, natal dispersal should be strongly biased towards males in species with pronounced female philopatry (Dobson, 1982; Greenwood, 1983; Pusey \& Packer, 1987; Lawson Handley \& Perrin, 2007).

Although there is strong evidence supporting the link between dispersal patterns and mating systems (Harcourt et al., 1976; Fredsted et al., 2007; Nagy et al., 2007; Zedrosser et al., 2007; Arlt \& Pärt, 2008), the traditional explanations for the evolution of dispersal patterns cannot account for all of the observed variation among primate taxa (Moore, 1984, 1992; Moore \& Ali, 1984; Glander, 1992; Wright, 1995; Pope, 2000; Radespiel et al., 2003; Jack \& Fedigan, 2004a,b; Boinski, 2005; Ekernas \& Cords, 2007). It has become clear that male-biased dispersal and female philopatry is not a 'typical' primate pattern (Strier, 1994, p. 239). Approximately half of the polygynous or polygamous primate species exhibit dispersal by both sexes (Strier, 1994), and there is significant evidence indicating that in monogamous mammals both sexes usually disperse (Dobson, 1982; Savage et al., 1996; Brockelman et al., 1998; Baker et al., 2002; Swilling \& Wooten, 2002; Reichard, 2003; Sun, 2003; Lappan, 2007; Ochiai \& Susaki, 2007).

I evaluate here whether owl monkeys, socially monogamous primates from Central and South America (Fernandez-Duque, 2007), show the expected pattern of bisexual dispersal and whether males and females differ in their natal dispersal patterns. All Aotus populations studied to date consist of relatively small social groups (2-6 individuals) that include one pair of reproducing adults and a few young (Wright, 1994; Fernandez-Duque, 2007). The reproducing pair occupies a relatively small and exclusive territory (4-10 ha). Within their territory they forage primarily for fruits, but also obtain significant amounts of leaves, flowers and insects (FernandezDuque, 2007). Social groups interact aggressively with other groups at territory boundaries or with individuals who, after dispersing from their groups, are ranging solitarily among territories. These solitary individuals sometimes evict and replace the resident same-sex adult through aggressive interactions that may even lead to the death of some of the individuals involved. The process usually takes at least several days. The incoming individual wanders in the periphery of the group and over a period of a few or many days 
interacts aggressively with members of the group. The aggressive interactions may include chasing, grabbing, and biting. When the solitary individual is successful, he/she soon begins interacting affiliatively with other group members and within few days is fully accepted into the group. Male owl monkeys show intense care of the infants (Dixson \& Fleming, 1981; Wright, 1984; Rotundo et al., 2005; Wolovich et al., 2008). Most owl monkey species are strictly nocturnal, but the Azara's owl monkeys (A. azarai) of Argentina, Bolivia and Paraguay regularly show both diurnal and nocturnal activity (Wright, 1989; Fernandez-Duque, 2003; Fernandez-Duque \& Erkert, 2006). The diurnal activity of this species has enabled researchers to examine the behavioural ecology of owl monkeys in some detail (FernandezDuque, 2003; Fernandez-Duque \& Erkert, 2006; Fernandez-Duque et al., 2008; Wolovich et al., 2008).

A few years ago, when we could not yet sex or identify individuals reliably, we tentatively suggested that both male and female owl monkeys had a flexible dispersal strategy (Fernandez-Duque \& Huntington, 2002). Our limited data indicated that there was significant variation in age at dispersal; some individuals left their natal groups before or around the time of sexual maturation, whereas others showed delayed dispersal. At the time we were unable to offer explanations for those observations due to the limited data.

I now present data collected from 160 individuals in 28 social groups over 10 years to provide a detailed description of dispersal in the species, to evaluate the extent and characteristics of sex-biased natal dispersal and to examine the possible role of demographic and ecological factors on triggering natal dispersal. I consider the data in the context of the three main hypotheses that have been proposed to explain the evolution of dispersal: the inbreeding avoidance (Moore \& Ali, 1984; Pusey, 1987; Moore, 1992; Sillero-Zubiri et al., 1996), the mate competition, and the resource competition hypotheses (Isbell, 2004; Ochiai \& Susaki, 2007; Warner \& Shine, 2008). The inbreeding avoidance hypothesis states that natal dispersal functions to minimize the risks of mating with kin, whereas the competition avoidance hypotheses propose that natal dispersal occurs to minimize the costs of competing for mating opportunities or food resources within the group.

The confirmatory testing of these broad and non-exclusive hypotheses is not possible with the correlational data characteristic of field studies. Still, an examination of the relationships between demographic and environmental factors and dispersal patterns may allow us to identify possible mechanisms 
regulating the process of dispersal (Taborsky, 2008). If natal dispersal functions primarily as a mechanism to avoid inbreeding, there will be a strong association between dispersal and demographic changes in group composition. Dispersal will be more likely before or around the time of sexual maturation, and when the same-sex adult in the natal group dies or is replaced through eviction since both events will increase the chances of mating with kin (i.e., opposite-sex parent). On the other hand, the probability of natal dispersal will be lower if the opposite-sexed parent is replaced from the natal group, since this change in group composition will reduce the chances of mating with a putative parent. Under those circumstances, individuals of various ages will disperse at various times of the year, but not necessarily those times that may be more favorable to the dispersing animal from an environmental perspective (e.g., food availability). The timing of dispersal will not be markedly seasonal since dispersal will be primarily triggered by relatively infrequent non-seasonal intra-group social changes.

On the other hand, if natal dispersal is primarily a mechanism to avoid competition for mates, dispersal will occur once the predispersing individual has reached sexual maturation, since it is then that intra-group mate competition will be most intense. Under this hypothesis, dispersal events will be concentrated around the mating season when competition for mates within the group or access to potential mates outside the group is highest. Finally, if the function of natal dispersal is to reduce competition for food resources, the timing of dispersal will be tightly linked to the seasonal nature of food availability in the Gran Chaco. In this scenario, animals will disperse after having experienced a period of scarcity within the group or in anticipation of abundant resources that can ease the difficulties of ranging solitarily.

\section{Methods}

\section{Study area and population}

The area of study is located in the Guaycolec Ranch, $25 \mathrm{~km}$ from the city of Formosa in the Argentinean Gran Chaco of South America $\left(58^{\circ} 11^{\prime} \mathrm{W}\right.$, $\left.25^{\circ} 58^{\prime} \mathrm{S}\right)$. The region consists of a matrix of grasslands dotted with patches of forests and is transected by gallery forests that grow along rivers. Owl monkeys (A. azarai) inhabit the gallery forests that grow along the Pilagá 
and Guaycolec rivers, as well as the patches of forests immersed in the grasslands.

We have monitored the population regularly since 1997 (FernandezDuque et al., 2001). We have darted and captured 140 individuals in the population to fit them a radiocollar or a bead collar for identification purposes (Fernandez-Duque \& Rotundo, 2003). Between June 1997 and March 2008 we recorded the birth of 160 individuals born in 28 social groups. Thirty individuals born in 14 groups that occupy territories in the periphery of the main study area were dropped from the analyses, since we did not have reliable data on the dates of their birth, dispersal or disappearance. A further 28 individuals were not included in the analyses presented here because they disappeared from their natal group when they were still too young to infer they had dispersed (less than 1.6 years old) and it is assumed that they died. The remaining 102 individuals provided the information presented here ( $N=24$ groups). Only eight individuals from our previous analyses are included within the new data set (Fernandez-Duque \& Huntington, 2002).

\section{Ecological data}

The study area is seasonal, characterized by significant fluctuations in rainfall, temperature, and food productivity. Rainfall records were obtained from the Estancia Guaycolec. Monthly average rainfall for the period 1977-2007 varied significantly during the year, with two rain peaks in April and November, and a relatively dry season lasting from June to August (Figure 1a). Hourly temperatures, recorded using a Stowaway XTI temperature automatic data logger during 1999-2007, were used to compute day and monthly temperature means. Monthly mean temperatures were on average $11^{\circ} \mathrm{C}$ lower during the Fall/Winter months than they were during Spring/Summer months (Figure 1b).

Food availability was also variable across the year. To evaluate changes in the relative abundance of insects through the year we used insect light-traps (Smythe, 1997) placed at five and ten meters on a tree. We left each trap on all night (1800-0600 h) twice a month during a year. The weight of captured insects was considerably higher between September and March than it was between April and August (Fernandez-Duque, 2003). To evaluate seasonal changes in the availability of plant resources, we recorded the presence and abundance of leaves, flowers, and fruits in the crown of 1000 trees distributed in 30 plots $(50 \times 10 \mathrm{~m})$ randomly placed in approx. 30 ha of forest 

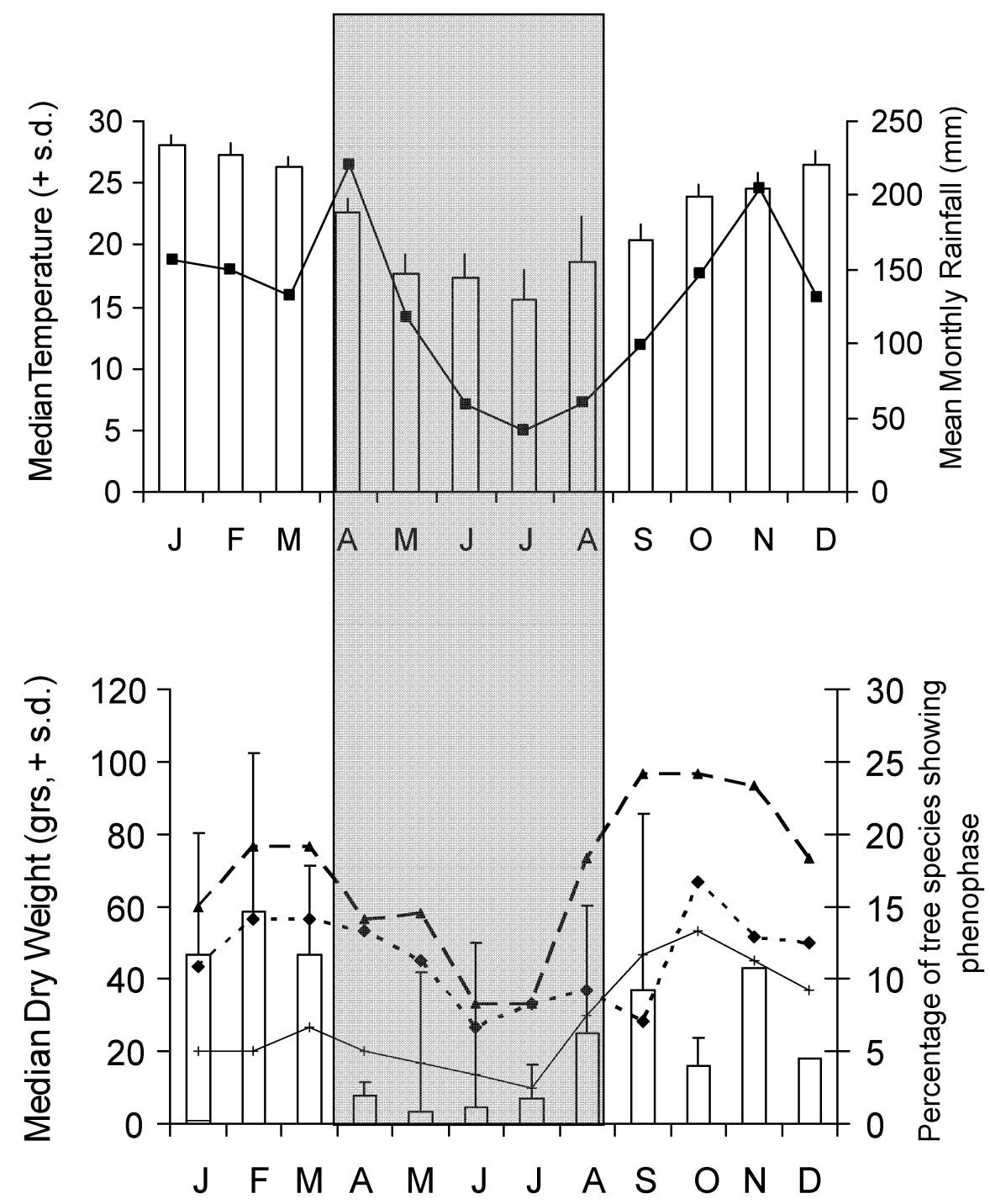

Figure 1. (a) Annual variation in monthly median temperature (1998-2007; represented by bars) and mean monthly rainfall (1977-2007, squares) at Estancia Guaycolec, Formosa Province, Argentina. (b) Seasonal changes in dry weight of captured insects (bars) and in the percentage of tree species showing new leaves (black solid triangles), fruits (black cross marks) and flowers (black solid diamonds). The Fall/Winter months are indicated with the gray box. The months of the year are indicated with the first letters of each month (e.g., J for January). 
(Fernandez-Duque et al., 2002). The percentage of tree species producing fruits, flowers or new leaves reached a low in the coldest and driest months of June and July; whereas a higher percentage of species produced fruits, flowers and new leaves beginning in September.

\section{Data analysis}

In the analyses below, I identify distinct periods during the year using ecological or reproductive data. First, the differences in rainfall, temperature, and food productivity determine a Fall/Winter period from April to August ( $N=5$ months), and a Spring/Summer one from September to March ( $N=7$ months, Figure 1). Second, the strong seasonality of ecological factors is probably associated with the timing of mating and births in the population. The birth season occurs between late September and late November (Fernandez-Duque et al., 2002) following a mating season that lasts approximately from April to June (Figure 1).

We recorded the birth dates of individuals born during the study to the nearest month. We classified individuals as infants (0-11 months), juveniles (12-23 months), non-reproducing adults ( $>23$ months and still in natal group) and reproducing adults ( $>23$ months and not in natal group). We are usually able to estimate a relatively narrow age range for infants and juveniles since all births in the population occur between October and January (Fernandez-Duque et al., 2002) and owl monkeys are unequivocally of smaller size until they are 18 months old (Fernandez-Duque et al., 2001). The inter-birth interval in the population is approximately one year determined by a marked birth seasonality. The classification of individuals as non-reproducing or reproducing adults is more difficult. Individuals do not reach full body mass or exhibit a fully developed sub-caudal gland until they are approximately four years of age (Juárez et al., 2003; Fernandez-Duque, 2004). The few individuals who have been followed since birth have not reproduced until they were at least 5 years old. Because we have not yet examined the hormonal correlates of development we do not know whether our category of non-reproducing adults includes individuals who are cycling or not.

Non-reproducing individuals missing from their natal group were classified as dispersed (i.e., confirmed dispersal), disappeared (i.e., presumed dispersal) or dead. Individuals were classified as dispersed when they were 
observed at least once outside the natal group. That is, they were observed ranging solitarily in the periphery of the natal territory, ranging over other territories, or as members of a new group. Disappeared individuals were those who were never observed again after they were missing from their natal group, and given their pre-dispersal behavioural patterns and/or their age it was reasonable to assume they had dispersed. Dead individuals were those who were found dead (i.e., their corpse was recovered), or were never observed again after last seen in the natal group and because of their age (less than 1.6 years of age), and behaviour was reasonable to assume they had died during dispersal.

I considered a dispersal event as a change in group composition due to a confirmed dispersal, a presumed dispersal or the death of a non-reproducing individual while it was dispersing or at a time when it was showing behavioural patterns associated with dispersal. I analyzed the annual distribution of dispersals assigning observations to one-month periods. I treated each dispersal event as occurring at the midpoint of the period between the last time the individual was seen in the group and the first time the individual was noted as missing from its natal group.

I estimated the median age at natal dispersal in two different manners. First, I determined it precisely for the collared individuals of known date of birth and sex who dispersed during the study (19 males, 14 females). Second, I estimated age-specific probabilities of dispersal for all individuals who dispersed when they were at least 16 -months-old $(N=79)$ using KaplanMeier cumulative survivorship estimates (SPSS 15.0). Kaplan-Meier estimates use right-censored data, in which some individuals have not yet experienced the event of interest at the end of the observation period. In the present context, a right-censored observation indicates that the individual was still resident in the natal group by the end of the study period. These individuals are treated as disappearing in an open interval after March 2008. The estimation also uses left-truncated data which refers to data in which some individuals were unavailable for observation of the event of interest at early ages. In this context, a left-truncated observation is that of an individual born before the study began. At the beginning of the study there were 16 juveniles or infants present from the 1995 or 1996 birth seasons. These observations are left-truncated because any disappearances or mortality that might have taken place prior to June 1997 would not have been observed. 
Estimating the dispersal distance poses some serious challenges. When animals disperse outside the study area, even while wearing radio-collars, they may not be located again. Thus, estimates of dispersal distance based on the observation of dispersing animals will tend to be underestimates. Here I present estimates of dispersal distance for 19 radiocollared individuals that were followed from the moment they left their natal group until they entered a new group, they died, or they disappeared from our area of study, with the understanding that these estimates are preliminary and likely underestimate dispersal distances. The distance was estimated from the center of the natal territory to the center of the territory where they established themselves, or to the location where they were found dead.

\section{Results}

Table 1 provides the sample sizes for the various categories of individuals being considered in this section.

\section{Timing of dispersal}

I report the timing of 52 dispersals (confirmed and presumed) to the nearest month $(N=41)$ or to a two-month period $(N=11)$. Of the dispersals 16 were not included in the analysis since they could not be well-timed.

Dispersals (i.e., confirmed and presumed dispersals plus deaths most likely occurring during dispersal) occurred in all months, but were concentrated between September and March (43/52, 83\% of all dispersals) with a marked peak in October $(16 / 52,31 \%$, Figure 2). Dispersals were less frequent between April and August $(9 / 52,17 \%)$ reaching a minimum in April

Table 1. Number of males and females who were still in their natal group at the end of the study, who had dispersed and who were presumed to have dispersed.

\begin{tabular}{lcccr}
\hline & Male & Female & Unsexed & Total \\
\hline Not dispersed & 2 & 4 & 28 & 34 \\
Confirmed dispersal & 19 & 14 & 0 & 33 \\
Presumed dispersal & & & 35 & 35 \\
Total & 21 & 18 & 63 & 102 \\
\hline
\end{tabular}




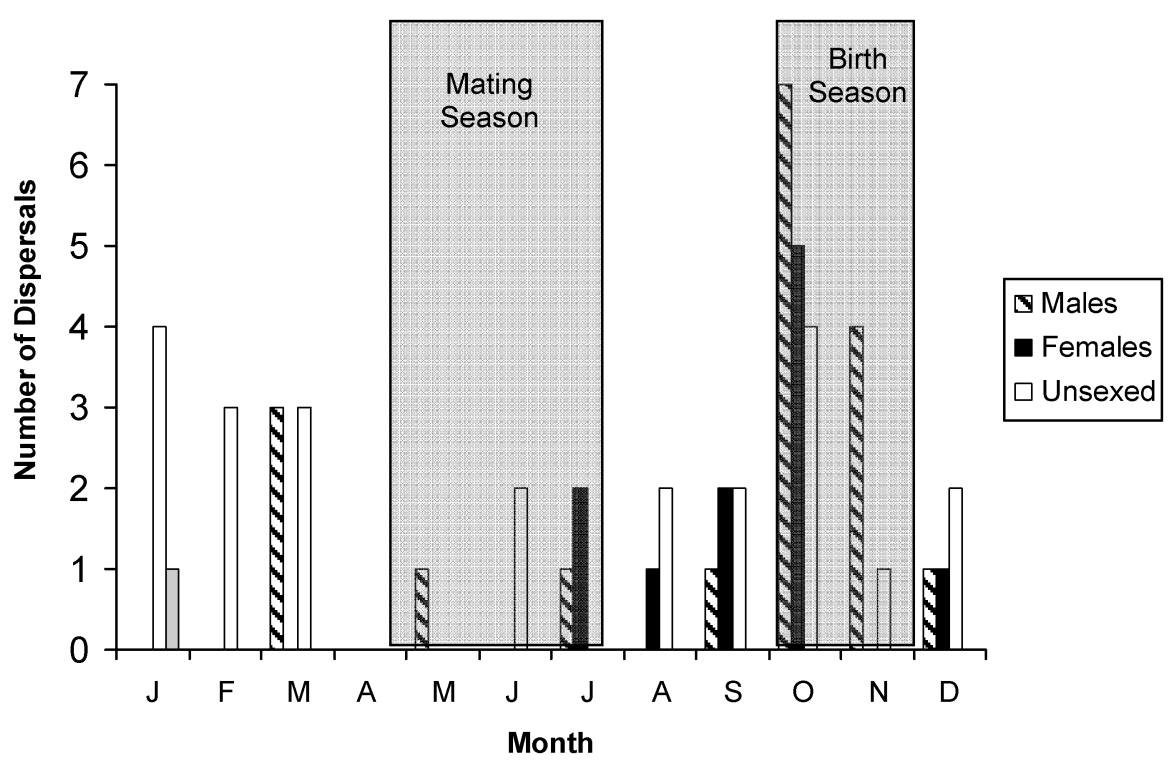

Figure 2. Annual distribution of natal dispersals of males, females and unsexed individuals. The mating and birth seasons are indicated by gray boxes. The months of the year are indicated with the first letters of each month (e.g., J for January).

when no dispersals occurred. The difference in the number of dispersals between the Fall/Winter $(N=43)$ and Spring/Summer $(N=9)$ periods was statistically significant $\left(\chi^{2}=24\right.$, df $\left.=1, p<0.000\right)$. Most individuals dispersed during or after the birth season $(21 / 52,40 \%)$, whereas very few of them did so during the mating season $(3 / 52,6 \%)$.

Males and females dispersed most frequently in October $(7 / 18$ and $5 / 11$, respectively). Seventy percent of males (16/18) and $70 \%$ of females $(8 / 11)$ dispersed between September and March. Unsexed individuals followed the same pattern, dispersing usually during Spring/Summer (19/23), with a tendency to disperse the most in October (4/23). Despite a general similarity between the sexes, the distribution of dispersal events seemed to be more seasonal for females than males. Most females (10/11) dispersed in a fourmonth period (July-October), whereas males dispersed at all times of the year. Both males and females dispersed more frequently during or after the birth season, than they did during the mating season.

The probability of an animal dispersing during the Fall/Winter period was higher following changes in group composition. This was specifically true following the replacement of one of the adults in the group. Very few indi- 
viduals dispersed during the Fall/Winter $(11 \%, 2 / 19)$ when the pair of adults remained stable. On the other hand, the proportion of individuals dispersing during this period increased $(35 \%, 6 / 16)$ following the replacement of one of the adults.

Although a large number of dispersal events occurred after the replacement of one of the reproducing adults (51\%), there was also an almost equal proportion of individuals who dispersed without drastic changes in group composition (49\%). There were no obvious differences in the probability of females and males dispersing following the eviction of the opposite-sex putative parent.

\section{Age of natal dispersal}

All individuals, males and females, eventually dispersed from their natal groups. In other words, no individual remained in its natal group to inherit the territory and reproduce. Males and females did not differ in the median age at dispersal (males $3.1 \pm 0.8$ years, $N=21$, females $3.1 \pm 0.9$ years, $N=18$ ) when computed for the individuals of confirmed dispersal. The dispersal age of the unsexed individuals $(3.0 \pm 0.1, N=35)$ was quite similar. When both confirmed and presumed dispersed individuals are included in the analysis, there is still no significant sex difference in the median age of natal dispersal (males $3.4 \pm 0.3$, females $3.2 \pm 0.2$; Figure 3 ).

There was significant variation on the age of dispersal among individuals. Some animals dispersed before the age when they usually reach adult body mass (approx. 3 years, unpublished data), and others well after having done so, but they all did it before reproducing. The youngest animal to disperse was a 2.2-year-old male, and the oldest confirmed dispersal was a 4.9-yearold female. A presumed dispersal of a 5.4-year-old female is tentative, since her date of birth was not precisely determined. There was a tendency for males to begin dispersing at a younger age than females and for females to continue dispersing until an older age. This is illustrated in Figure 3, where the proportion of individuals dispersing between two and three years of age is larger for males than females. The youngest female dispersed at 2.75 years, whereas eight males dispersed when they were that age or younger. On the other hand, the proportion of individuals dispersing between 4 and 5 years is larger for females than males. Three females dispersed when they were 4.1, 4.9 and 5.4 years, whereas all males had dispersed by the age of 4 years. 


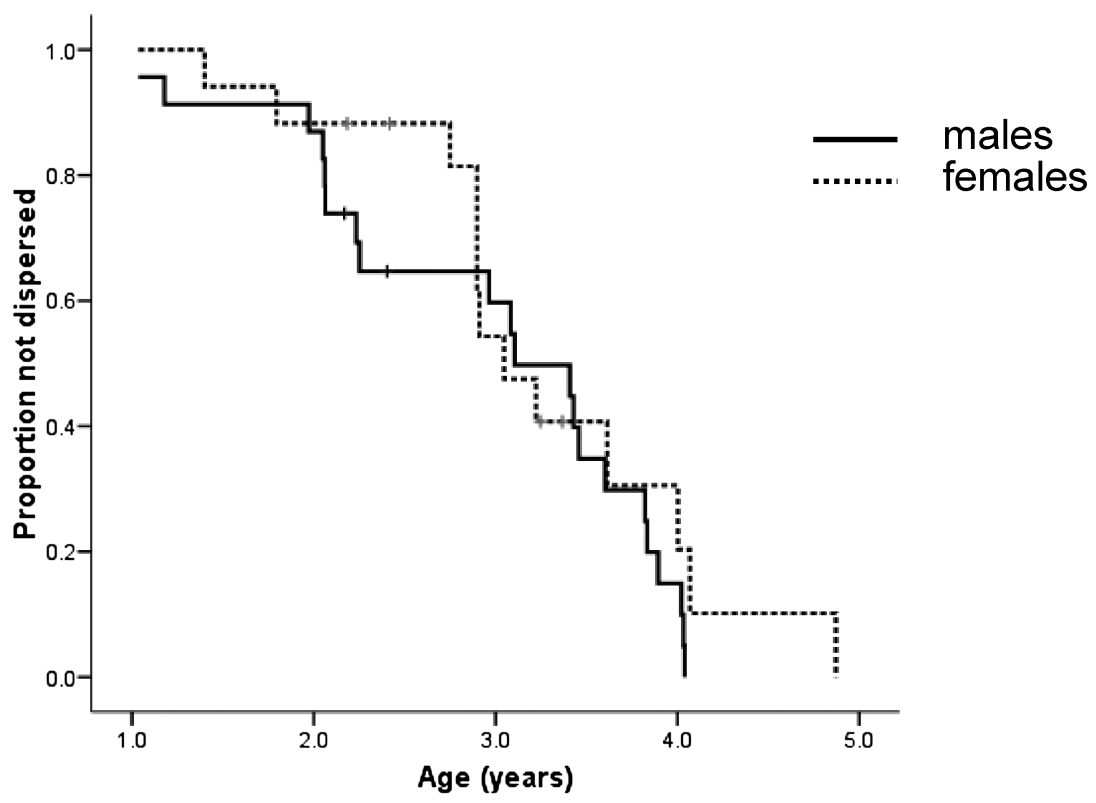

Figure 3. Age-specific probabilities of dispersal for all individuals who were missing in their natal groups when they were at least 16 months old $(N=79)$. The two curves show the changes with age in the proportion of males and females who have not dispersed from their natal groups. The halfway point along each of the curves is the median age of natal dispersal for each sex.

Animals dispersing during the Fall/Winter period or mating season months tended to be younger than those dispersing during the Spring/Summer or birth season months (Figure 4). The differences in age of dispersal across months were statistically significant as indicated by a one-way analysis of variance $(F=2.278, \mathrm{df}=11, p=0.020)$.

\section{Natal dispersal distance}

Three males and four females dispersing from five different social groups were successfully followed until they entered a new group (Table 2). Four of them dispersed to a territory sharing a common border, whereas the remaining ones dispersed to groups located three $(N=1)$ or four territories away $(N=2)$.

There were no marked sex differences in the distance traveled during dispersal. Still, given the small sample size and the likely underestimation, the evaluation of sex differences in dispersal distances should be considered 


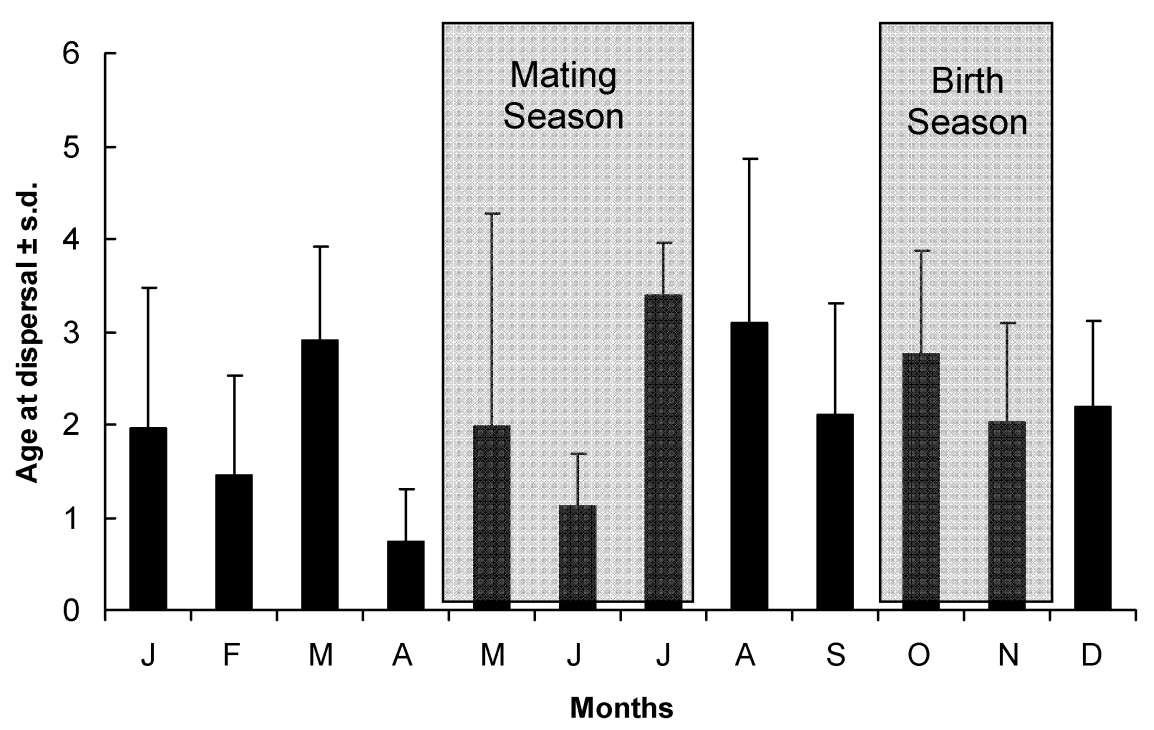

Figure 4. Annual variation in the median age at dispersal.

with caution. Two males and one female dispersed much further than the rest of the animals (Table 2), whereas two males and two females dispersed to neighbouring groups $(299 \mathrm{~m}$ and $185 \mathrm{~m})$.

A brother and a sister dispersed to the same neigbouring group, but at different times. The female dispersed on September 2004 when she was 2.9 years. She became the resident female and remained in her new group until September 2005 when she was evicted. Her brother dispersed on October 2005 when he was 3.0 years old and became the resident male. Unfortunately we did not witness interactions between the two siblings to document the process.

Four females and five males were regularly monitored while dispersing until they disappeared from the area of study. While dispersing, males and females did not differ in how far they ranged from their natal groups as indicated by the maximum distance recorded from the center of their natal territory. The median maximum recorded distance for males $(656 \mathrm{~m})$ was not significantly different than the distance recorded for females $(667 \mathrm{~m})$.

\section{Fate of dispersed individuals}

Only a limited number of individuals $(N=19)$ contributed conclusive information about their fate following natal dispersal (Table 2). Four males and 
Table 2. Natal dispersal age (years), fate and distance (meters) of 20 radiocollared individuals.

\begin{tabular}{|c|c|c|c|c|c|}
\hline Subject name & Natal group & Sex & Age at dispersal & Fate & Distance \\
\hline Diosa & D500 & q & 2.9 & New group & 299 \\
\hline Diuresis & D500 & q & 4.9 & New group & 811 \\
\hline Mony & Cola Corta & q & 3.6 & New group & 262 \\
\hline Anibal & Colman & $\sigma^{7}$ & 3.1 & New group & 1221 \\
\hline Dardo & D1200 & $0^{x}$ & 3.6 & New group & 185 \\
\hline Dionisio & D500 & $\sigma^{x}$ & 3.0 & New group & 299 \\
\hline Felix & F700 & $0^{7}$ & 2.2 & New group & 995 \\
\hline Conchita & Cola Corta & q & 2.9 & Disappeared & 741 \\
\hline Mabela & B68 & 우 & na & Disappeared & 446 \\
\hline Manchita & B68 & q & na & Disappeared & 593 \\
\hline Vilma & Veronica & q & na & Disappeared & 962 \\
\hline Apolo & A900 & $\sigma^{7}$ & 3.4 & Disappeared & 656 \\
\hline Camilo & Campamento & $\sigma^{7}$ & 4.0 & Disappeared & 2243 \\
\hline Dante & D1200 & $\sigma^{x}$ & 4.0 & Disappeared & 446 \\
\hline Dartagnan & D1200 & $0^{x}$ & 3.4 & Disappeared & 412 \\
\hline Fidel & Fauna & $\sigma^{7}$ & 2.1 & Disappeared & 657 \\
\hline Angelita & Colman & q & 2.8 & Dead & $0^{*}$ \\
\hline Dina & D500 & q & 3.0 & Dead & 600 \\
\hline Elegida & E500 & q & 4.0 & Dead & $0^{*}$ \\
\hline Candado & Campamento & $\sigma^{x}$ & 3.8 & Dead & 200 \\
\hline
\end{tabular}

na, unknown date of birth and, therefore, unknown age at dispersal.

${ }^{*}$ Found within the natal territory.

three females entered neighbouring groups and have successfully reproduced since then. Three females and one male died during dispersal. Although we recovered the corpses and/or collars soon after their death, we have no conclusive evidence regarding the cause of their death. We found the male's collar in the grassland near his natal territory, possibly indicating that he died nearby. Two of the females were found within their natal territories. One of the females dispersed from her group following some significant changes in group composition that led to her dispersal, the dispersal of her older sister and the eviction of their mother. While she wandered near the territory for a few days, we observed her and noticed some wounds. A few days later we found her dead. It is very likely that she was wounded during aggressive interactions with other individuals during the dramatic changes in group composition. Sometimes the eviction of one of the adults through aggressive interactions may trigger the dispersal of other non-reproducing individuals. 
The skeleton of a second female was found inside a burrow within her natal territory. She had been observed wandering in the periphery of the territory. The third female was found dead three territories away from her natal territory.

\section{Discussion}

The depiction of dispersal as a species-specific static process is no longer tenable; dispersal is now rightfully considered the "consequence of dynamic, and often nonintuitive interactions among multiple-tradeoffs that may vary across individual, sex, age, dominance, social groups, species, habitat, and historical origins and contemporary disturbances" (Boinski, 2005). It has been shown that even within the same genus, the form of natal dispersal may vary depending on ecological, social and demographic factors (Jack \& Fedigan, 2004a,b; Boinski, 2005). Some time ago we suggested that owl monkeys were following a flexible dispersal strategy influenced by ecological, demographic and behavioural factors (Fernandez-Duque \& Huntington, 2002). Here I have presented data from a large number of identified individuals living in numerous social groups that support our previous findings.

In the following paragraphs I first evaluate how demographic and ecological factors may be related to the observed dispersal patterns in owl monkeys, including possible sex differences in the timing, distance, and fate of dispersing individuals. I then consider the results in the context of the three classic evolutionary hypotheses for natal dispersal.

\section{Timing of dispersal}

This study confirmed published data and theoretical expectations that both sexes disperse in this socially monogamous species of owl monkeys (Aotus azarai). Also in agreement with our previous findings, owl monkeys showed a flexible dispersal strategy that seems to be responsive to various ecological and demographic factors. Although the timing of dispersals was markedly concentrated around the month of October, no single explanation can easily account for this pattern. Both demographic and ecological factors can be related to the observed pattern since this month corresponds to the beginning of the birth season, but also to the beginning of the Spring/Summer season when food is most abundant. 
Demographic factors seem to be influencing to some extent the triggering of natal dispersal within and across groups in the population. Sudden, relatively infrequent, dramatic changes in group composition, like the eviction of the resident male or female by an incoming adult, occurred in strong association with dispersal events. In these cases, the timing of dispersal was spread through the year, possibly occurring at times less than ideal for the dispersing animal. Dispersals associated with replacement of adults also included animals of a wider range of ages. Animals may have been forced to disperse when the relative costs of dispersal were high (e.g., low food availability, extreme low temperatures) because these costs are less than the costs associated with aggression from the new incoming adult (Fernandez-Duque, 2007).

The concentration of dispersals around the birth season raises the possibility that births within the group are triggering the process of dispersal. Still, the high frequency of dispersals in August and September, when the birth season has not yet started, provides better support for the role of ecological factors influencing the timing of dispersal. Future analyses of the relationship between the occurrence of births and dispersal, as well as the behavioural interactions between parents and predispersing juveniles may help elucidate a potential causal relationship between the birth season and the timing of dispersal.

It is also possible that changes in the composition of neighbouring groups may contribute to dispersal if dispersing animals were communicating their availability to mate or if they were able to detect a potential reproductive opening in another group. This is an explanation quite difficult to evaluate because it requires the simultaneous observation of dispersing animals in neighbouring groups. Although we were not able to systematically evaluate this possible factor, on a few occasions we have observed pre-dispersing individuals wandering through territories for hours or days before returning to their natal territories and groups. For example, we recently followed a predispersing 4-year-old female as she wandered through three territories giving hoot calls. Hoot calls may function to attract potential mates (Wright, 1989; Depeine et al., 2008). She wandered for a few hours, and then returned to her natal territory and group. It seems likely that these activities allow pre-dispersing individuals to assess dispersal opportunities as it has been described in other primate species (Jack \& Fedigan, 2004a). 


\section{Natal dispersal distance}

A sex bias in natal dispersal distance could function as a mechanism leading to separation of siblings and, thus, inbreeding avoidance (Eikenaar et al., 2008). In our population we still have no evidence for sex differences in dispersal distance. Several of the individuals dispersed very close to their natal group. The case of the two siblings going to the same neigbouring group, but at different times, provides some interesting information on this regard. Here dispersal distance clearly did not function as a sufficient mechanism to prevent kin from becoming reproductive individuals in the same group. On the other hand, the fact that the sister left her new group soon after her brother entered it opens the possibility that there were kin-recognition behavioural mechanisms that prevented the two of them holding reproductive positions in the same group at the same time. Dispersal into neighbouring groups has been reported for capuchin monkeys (Jack \& Fedigan, 2004a), but it should be noted that those species range over significantly larger areas and live in multi-male multi-female groups. In other words, even when dispersing to neighbouring groups, individuals in those species are likely to encounter non-related individuals. The situation is probably more extreme in socially monogamous taxa, where the number of potential mates in a group is reduced to one.

On the other hand, the prevalence of dispersal to the nearest territories could well be an artifact of our limitations to detect dispersal outside the study area. In fact, we were able to identify two males relatively far from their natal groups suggesting that there may be individuals dispersing much father that go undetected.

\section{Fate of dispersed individuals}

The fate of dispersed individuals remains one of the least understood aspects of the process of natal dispersal. The significant attrition in the sample sizes of dispersing individuals continues to limit our understanding. Although we began the analysis following 102 identified individuals, we only succeeded in obtaining confirmatory evidence for the fate of dispersed individuals from $10 \%$ of them (11/102). Seven individuals entered new groups and reproduced, whereas four died while dispersing. The remaining ones belong in the unsatisfying category of 'disappeared' while dispersing. 
The evidence indicates that the time of dispersal is a high-risk period in the life of owl monkeys. We have argued elsewhere that the juvenile and prereproductive period may be the most dangerous ones for owl monkeys, as is the case for most primates (Isbell et al., 1990, 1993; Janson \& Van Schaik, 1993). Three animals were found dead within areas they normally ranged suggesting that the risks are not exclusive to venturing in unknown areas. Dispersing individuals often experience aggression from other groups, may be less efficient in foraging and more exposed to unknown predators (Pusey \& Packer, 1987). In our study population we have not yet witnessed any predation events, but we have seen owl monkeys interacting aggressively with tayras (Eira barbara).

\section{Preliminary evaluation of the inbreeding and competition avoidance hypotheses}

How well do the hypotheses under consideration explain our data? In examining the validity of the various hypotheses we should be aware that a coincidence between qualitative predictions and the data does not reveal the causal mechanisms underlying the relationship (Taborsky, 2008). The hypotheses under consideration most likely exclude a large number of potential important factors influencing the observed pattern. Thus, the data presented, when examined in the general theoretical framework of these hypotheses will help us formulate in the future quantitative and directional predictions that may bring us closer to identifying causal relationships among the factors under consideration.

Some of the data are in good support of the inbreeding avoidance hypothesis. If natal dispersal functions primarily as a mechanism to avoid inbreeding, one expects individuals to disperse around the time of sexual maturation. Although the age at dispersal varied widely, all individuals dispersed before reproducing. Additional evidence for this hypothesis comes from the unexpected interaction between a 4-year-old female and her putative father. This female had been showing predispersal behavioural patterns, including the wandering outside her natal group on several occasions. We had not observed any interactions between her and the adult male (the male present at the time when she was born) suggesting that she could be sexually receptive. Thus, it was very surprising to observe the adult male approach and mount her as soon as she had fallen asleep because of a tranquilizing dart. 
Since non-sexual mounting is not common in owl monkeys, we could interpret the observation as suggesting that the behavioural mechanisms that would normally prevent the potential reproduction between putative father and daughter had been turned off as the daughter was anesthesized.

Under this hypothesis, I also expected a strong association between the occurrence of dispersal and changes in the adult composition that could modify kinship relationships in the group. For example, I predicted that the probability of natal dispersal would be lower if the opposite-sexed parent had been replaced from the natal group because there would be no risk of mating with a parent. In fact, changes in group composition were associated with dispersal events. For example, following the replacement of one of the adults in the group, more individuals dispersed during the less preferred time of the year (Fall/Winter). But the data do not indicate that predispersing animals whose opposite-sex parent had been replaced were less likely to disperse choosing instead to stay with a potential mate.

A second hypothesis proposes that natal dispersal functions to prevent competition for food. In our population most animals dispersed when food becomes more abundant, indicating that, at least in the very short term, a shortage of food does not seem to be tightly linked to dispersal. If animals are dispersing because there is not enough food resources in their natal group, dispersals should be occurring sometime during the Fall/Winter when resources are at the lowest. On the other hand, it is also possible that the effects of a shortage of food during Fall/Winter are felt at the beginning of Spring/Summer when animals begin to disperse. The shortage of food could only be felt after several months and given that dispersed individuals need to range solitarily for a few weeks to many months before moving into a new group, it is possible that dispersal is taking place during the Spring and Summer months when temperatures are not as harsh and food resources more abundant (Fernandez-Duque et al., 2002). The dispersing individuals have not reached yet their full-size body (unpublished data) and dispersing is a challenging period during which they will be challenged and attacked by resident adults. In other words, there are high costs associated with natal dispersal that can be minimized if dispersal takes place at a time when food is abundant and temperatures are milder. Ongoing analyses to evaluate the relationship between increases in group size (through the birth of infants) and dispersal would provide additional data to evaluate the local resource competition hypothesis. 
Finally, it is possible that animals are dispersing to avoid competition for mates. Under this scenario, we should see animals dispersing once they are sexually mature or capable of outcompeting other individuals. I predicted that following the replacement of an adult in the group, individuals of the same-sex as the intruder would be more likely to disperse since the intruder represents mate competition, whereas opposite-sex individuals may actually represent potential reproductive partners and would, therefore, be tolerated. I also predicted that the timing of dispersal would be concentrated around the mating season when opportunities for reproducing may be highest. The data do not support these predictions. Although some animals dispersed at 4 or 5 years of age when they were probably ready to reproduce, some individuals also dispersed at an age when it is unlikely they were sexually mature. Regarding the timing of dispersal, most dispersal events occurred during the birth season when females were lactating and, therefore, not available as potential partners.

Our understanding of the behaviour and ecology of owl monkeys has improved significantly since we first attempted to explain the observed pattern of disappearances. Not only must we consider ecological, demographic and behavioural patterns, but it is becoming clear that there are important differences among years in the ecology of the Chaco that may have a profound impact on demographic parameters, which in turn will impact the behavioural tendencies of individuals. The last ENSO (El Niño Southern Oscillation) of 1996-1998 caused particularly wet years in the region, with annual rainfall being significantly higher during those years $(2045,1653$ and $1855 \mathrm{~mm}$, respectively) than the historical average for the region (1500 mm, 1977-2008). I am under the impression that those heavy rains and the following huge production of fruits may be related to the highest-ever rate of births recorded in 1999. In turn, that unusual birth peak may have produced a surplus of predispersing individuals during the years that most of our data were collected (2002-2005). In other words, any analysis of dispersal patterns must acknowledge that populations cycle and that the length of our studies (even if 10-years long) provides us with just a snapshot of the population's history.

\section{Acknowledgements}

Thanks to all the students, volunteers and assistants who contributed to the collection of the demographic data. Special gratitude to Marcelo Rotundo for his assistance in the field during 
all these years. I also thank Mr. F. Middleton, Manager of Estancia Guaycolec and Ing. C. Cimino (Bellamar Estancias) for the continued support of the Owl Monkey project. The Ministerio de la Producción, Subsecretaría de Ecología and Recursos Naturales and Dirección de Fauna from Formosa Province provided permits to conduct the research. I gratefully acknowledge financial support during all these years from the Wenner-Gren Foundation, the L.S.B. Leakey Foundation, the National Geographic Society, the National Science Foundation and the Zoological Society of San Diego.

\section{References}

Arlt, D. \& Pärt, T. (2008). Sex-biased dispersal: a result of a sex difference in breeding site availability. - Am. Nat. 171: 844-850.

Baker, A.J., Bales, K.L. \& Dietz, J.M. (2002). Mating system and group dynamic in lion tamarins. - In: Lion tamarins. Biology and conservation (Kleiman, D.G. \& Rylands, A.B., eds). Smithsonian Institution Press, Washington, DC, p. 188-212.

Boinski, S. (2005). Dispersal patterns among three species of squirrel monkeys (Saimiri oerstedii, S. boliviensis and S. sciureus): I. Divergent costs and benefits. - Behaviour 142: 525-632.

Brockelman, W.Y., Reichard, U., Treesucon, U. \& Raemaekers, J.J. (1998). Dispersal, pair formation and social structure in gibbons (Hylobates lar). - Behav. Ecol. Sociobiol. 42: 329-339.

Chepko-Sade, D.B. \& Halpin, Z.T. (1987). Mammalian dispersal patterns. The effects of social structure on population genetics. - The University of Chicago Press, Chicago, IL.

Clobert, J., Danchin, E., Dhondt, A.A. \& Nichols, J.D. (eds) (2001). Dispersal. — Oxford University Press, Oxford.

Depeine, C.C., Rotundo, M., Juárez, C.P. \& Fernandez-Duque, E. (2008). Hoot calling in owl monkeys (Aotus azarai) of Argentina: sex differences and function. - Am. J. Primatol. 70 (Suppl.): 69.

Dixson, A.F. \& Fleming, D. (1981). Parental behaviour and infant development in owl monkeys (Aotus trivirgatus griseimembra). - J. Zool. 194: 25-39.

Dobson, S.F. (1982). Competition for mates and predominant male dispersal in mammals. Anim. Behav. 30: 1183-1192.

Eikenaar, C., Richardson, D.S., Brouwer, L. \& Komdeur, J. (2008). Sex biased natal dispersal in a closed, saturated population of Seychelles warblers Acrocephalus sechellensis. J. Avian Biol. 39: 73-80.

Ekernas, S.L. \& Cords, M. (2007). Social and environmental factors influencing natal dispersal in blue monkeys, Cercopithecus mitis stuhlmanni. - Anim. Behav. 73: 1009-1020.

Fernandez-Duque, E. (2003). Influences of moonlight, ambient temperature and food availability on the diurnal and nocturnal activity of owl monkeys (Aotus azarai). - Behav. Ecol. Sociobiol. 54: 431-440.

Fernandez-Duque, E. (2004). High levels of intrasexual competition in sexually monomorphic owl monkeys. - Folia Primatol. 75 S1: 260.

Fernandez-Duque, E. (2007). The Aotinae: social monogamy in the only nocturnal haplorhines. - In: Primates in perspective (Campbell, C.J., Fuentes, A., MacKinnon, K.C., Panger, M. \& Bearder, S.K., eds). Oxford University Press, Oxford, p. 139-154. 
Fernandez-Duque, E. \& Erkert, H.G. (2006). Cathemerality and lunar periodicity of activity rhythms in owl monkeys of the Argentinian Chaco. - Folia Primatol.77: 123-138.

Fernandez-Duque, E. \& Huntington, C. (2002). Disappearances of individuals from social groups have implications for understanding natal dispersal in monogamous owl monkeys (Aotus azarai). - Am. J. Primatol. 57: 219-225.

Fernandez-Duque, E., Juárez, C. \& Di Fiore, A. (2008). Adult male replacement and subsequent infant care by male and siblings in socially monogamous owl monkeys (Aotus azarai). - Primates 49: 81-84.

Fernandez-Duque, E. \& Rotundo, M. (2003). Field methods for capturing and marking Azarai night monkeys. - Int. J. Primatol. 24: 1113-1120.

Fernandez-Duque, E., Rotundo, M. \& Ramírez-Llorens, P. (2002). Environmental determinants of birth seasonality in night monkeys (Aotus azarai) of the Argentinean Chaco. — Int. J. Primatol. 23: 639-656.

Fernandez-Duque, E., Rotundo, M. \& Sloan, C. (2001). Density and population structure of owl monkeys (Aotus azarai) in the Argentinean Chaco. - Am. J. Primatol. 53: 99-108.

Fredsted, T., Schierup, M.H., Groeneveld, L.F. \& Kappeler, P.M. (2007). Genetic structure, lack of sex-biased dispersal and behavioural flexibility in the pair-living fat-tailed dwarf lemur, Cheirogaleus medius. — Behav. Ecol. Sociobiol. 61: 943-954.

Glander, K.E. (1992). Dispersal patterns in Costa Rican mantled howling monkeys. - Int. J. Primatol. 13: 415-436.

Greenwood, P.J. (1983). Mating systems and the evolutionary consequences of dispersal. - In: The ecology of animal movement (Swingland, I.R. \& Greenwood, P.J., eds). Clarendon Press, Oxford, p. 116-131.

Harcourt, A.H., Stewart, K.S. \& Fossey, D. (1976). Male emigration and female transfer in wild mountain gorilla. - Nature 263: 226-227.

Isbell, L.A. (2004). Is there no place like home? Ecological bases of female dispersal and philopatry and their consequences for the formation of kin groups. - In: Kinship and behaviour in primates (Chapais, B. \& Berman, C., eds). Oxford University Press, New York, NY, p. 71-108.

Isbell, L.A., Cheney, D.L. \& Seyfarth, R.M. (1990). Costs and benefits of home range shifts among vervet monkeys (Cercophitecus aethiops) in Amboseli National Park, Kenya. Behav. Ecol. Sociobiol. 27: 351-358.

Isbell, L.A., Cheney, D.L. \& Seyfarth, R.M. (1993). Are immigrant vervet monkeys, Cercopithecus aethiops, at greater risk of mortality than residents? - Anim. Behav. 45: 729-734.

Jack, K.M. \& Fedigan, L. (2004a). Male dispersal patterns in white-faced capuchins, Cebus capucinus: Part 1: patterns and causes of natal emigration. - Anim. Behav. 67: 761769.

Jack, K.M. \& Fedigan, L. (2004b). Male dispersal patterns in white-faced capuchins, Cebus capucinus: Part 2: patterns and causes of secondary dispersal. - Anim. Behav. 67: 771-782.

Janson, C. \& Van Schaik, C. (1993). Ecological risk aversion in juvenile primates. Slow and steady wins the race. - In: Juvenile primates. Life history, development and behaviour (Pereira, M.E. \& Fairbanks, L.A., eds). Oxford University Press, New York, NY, p. 57-74.

Johnson, M.L. \& Gaines, M.S. (1990). Evolution of dispersal: theoretical models and empirical tests using birds and mammals. — Annu. Rev. Ecol. Syst. 21: 449-480. 
Juárez, C., Rotundo, M. \& Fernandez-Duque, E. (2003). Behavioural sex differences in the socially monogamous night monkeys of the Argentinean Chaco. - Rev. Ethol. 5 (Suppl.): 174.

Lappan, S. (2007). Patterns of dispersal in Sumatran siamangs (Symphalangus syndactylus): preliminary mtDNA evidence suggests more frequent male than female dispersal to adjacent groups. - Am. J. Primatol. 69: 692-698.

Lawson Handley, L.J. \& Perrin, N. (2007). Advances in our understanding of mammalian sex-biased dispersal. — Mol. Ecol. 16: 1559-1578.

Moore, J. (1984). Female transfer in primates. — Int. J. Primatol. 5: 537-589.

Moore, J. (1992). Dispersal, nepotism, and primate social behaviour. — Int. J. Primatol. 13: 361-378.

Moore, J. \& Ali, R. (1984). Are dispersal and inbreeding avoidance related? - Anim. Behav. 32: 94-112.

Nagy, M., Heckel, G., Voigt, C.C. \& Mayer, F. (2007). Female-biased dispersal and patrilocal kin groups in a mammal with resource-defence polygyny. — Proc. Roy. Soc. London B: Biol. 274: 3019-3025.

Ochiai, K. \& Susaki, K. (2007). Causes of natal dispersal in a monogamous ungulate, the Japanese serow, Capricornis crispus. - Anim. Behav. 73: 125-131.

Pope, T.R. (2000). The evolution of male philopatry in neotropical primates. - In: Primate males. Causes and consequences of variation in group composition (Kappeler, P.M., ed.). Cambridge University Press, Cambridge, p. 219-235.

Pusey, A.E. (1987). Sex-biased dispersal and inbreeding avoidance in birds and mammals. Trends Ecol. Evol. 2: 295-299.

Pusey, A.E. \& Packer, C. (1987). Dispersal and philopatry. — In: Primate societies (Smuts, B.B., Cheney, D.L., Seyfarth, R.M., Wrangham, R.W. \& Struhsaker, T.T., eds). The University of Chicago Press, Chicago, IL, p. 250-266.

Radespiel, U., Lutermann, H., Schmelting, B., Bruford, M.W. \& Zimmermann, E. (2003). Patterns and dynamics of sex-biased dispersal in a nocturnal primate, the grey mouse lemur, Microcebus murinus. - Anim. Behav. 65: 709-719.

Reichard, U.H. (2003). Social monogamy in gibbons: the male perspective. - In: Monogamy. Mating strategies and partnerships in birds, humans and other mammals (Reichard, U.H. \& Boesch, C., eds). University of Cambridge Press, Cambridge, p. 190-213.

Rotundo, M., Fernandez-Duque, E. \& Dixson, A.F. (2005). Infant development and parental care in free-ranging Aotus azarai azarai in Argentina. — Int. J. Primatol. 26: 14591473 .

Savage, A., Giraldo, L.H., Soto, L.H. \& Snowdon, C.T. (1996). Demography, group composition, and dispersal in wild cotton-top tamarins (Saguinus oedipus) groups. - Am. J. Primatol. 38: 85-100.

Sillero-Zubiri, C., Gottelli, D. \& Macdonald, D.W. (1996). Male philopatry, extra-pack copulations and inbreeding avoidance in Ethiopian wolves (Canis simensis). — Behav. Ecol. Sociobiol. 38: 331-340.

Smythe, N. (1997). The seasonal abundance of night-flying insects in a neotropical forest. In: The ecology of a tropical forest. Seasonal rhythms and long-term changes (Leigh, E.G.J., Rand, S.A. \& Windsor, D.M., eds). Smithsonian Institution Press, Washington, DC, p. 309-318.

Strier, K.B. (1994). Myth of the typical primate. — Yb. Phys. Anthropol. 37: 233-271. 
Sun, L. (2003). Monogamy correlates, socioecological factors, and mating system in beavers. - In: Monogamy. Mating strategies and partnerships in birds, humans and other mammals (Reichard, U.H. \& Boesch, C., eds). University of Cambridge Press, Cambridge, p. 138-146.

Swilling, W.R.J. \& Wooten, M.C. (2002). Subadult dispersal in a monogamous species: the Alabama beach mouse (Peromyscus polionotus ammobates). - J. Mammal. 83: 252259.

Taborsky, M. (2008). The use of theory in behavioural research. - Ethology 114: 1-6.

Warner, D.A. \& Shine, R. (2008). Determinants of dispersal distance in free-ranging juvenile lizards. - Ethology 114: 361-368.

Wolovich, C.K., Perea-Rodriguez, J.P. \& Fernandez-Duque, E. (2008). Food transfers to young and mates in wild owl monkeys (Aotus azarai). — Am. J. Primatol. 70: 211221.

Wright, P.C. (1984). Biparental care in Aotus trivirgatus and Callicebus moloch. — In: Female primates: studies by women primatologists (Small, M., ed.). Alan R. Liss, New York, NY, p. 59-75.

Wright, P.C. (1989). The nocturnal primate niche in the New World. - J. Human Evol. 18: 635-658.

Wright, P.C. (1994). The behaviour and ecology of the owl monkey. — In: Aotus: the owl monkey (Baer, J.F., Weller, R.E. \& Kakoma, I., eds). Academic Press, San Diego, CA, p. $97-112$.

Wright, P.C. (1995). Demography and life history of free-ranging Propithecus diadema edwardsi in Ranomafana National Park, Madagascar. — Int. J. Primatol. 16: 835-854.

Zedrosser, A., Stoen, O.-G., Saebo, S. \& Swenson, J.E. (2007). Should I stay or should I go? Natal dispersal in the brown bear. - Anim. Behav. 74: 369-376. 